It is suggested that at maximal osmolality, urinary calcium concentrations attained by the former would therefore be greater than those attained by the latter, and become high enough to precipitate calcium salts in otherwise normal urine.

This study was supported by grants from the South African Council for Scientific and Industrial Research, the Wellcome Trust, and the Staff Research Fund of the University of Capetown.

\section{REFERENCES}

Boyce, W. H., and King, J. S. (1959). Fed. Proc., 18, 1102.

Chen, P. S., Toribara, T. Y., and Warner, H. (1956). Analyt. Chem., 28, 1756.

Davalos, A. (1945). 7. Urol. (Baltimore), 54, 182.

Dempsey, E. F., Forbes, A. P., Melick, R. A., and Henneman, P. H. (1960). Metabolism, 9, 52.
Dodgson, K. S. (1961). Biochem. 7., 78, 312.

Flocks, R. H. (1939). 7. Amer. med. Ass., 113, 1466

Gershoff, S. N., and Prien, E. L. (1960). Amer. f. clin. Nutr., 8, 812.

Hodgkinson, A., and Pyrah, L. N. (1958). Brit. F. Surg., 46, 10.

Isaacson, L. C. (1963). S Afr. F. Lab. clin. Med., 9, 31.

- and Jackson, W. P. U. (1963). Clin. Sci., 24, 223.

Jackson, W. P. U., and Irwin, L. (1957). F. clin. Path., 10, 383.

King E. J W Wootton, I D. P. (1956). Micro-analysis in Medical Biochemistry, 3rd ed. Cnurchill, London.

Lathem, J. E., and King, J. S. (1963). F. Urol. (Baltimore), 89, 541.

Litin, R. B., Diessner, G. R., and Keating, F. R. (1961). Ibid., 86, 17

McIntosh, J. F., and Read, M. K. (1958). Ibid., 80, 272.

Miller, G. H., Vermeullen, C. W., and Moore, J. D. (1958). Ibid., 79, 607. Modlin, M. (1965). M.D. Thesis accepted at the University of Capetown.
- Isaacson, L. C., and Jackson, W. P. U. (1963). S. Afr. med. F., 37, 121.

Nicolaysen, R., Eeg-Larsen, N., and Malm, O. J. (1953). Physiol. Rev., 33, 424.

Prien, E. L., and Frondel, C. (1947). F. Urol. (Baltimore), 57, 949.

Prince, C. L., Scardino, P. L., and Wolan C. T. (1956). Ibid., 75, 209.

Vermooten, V. (1941). Ibid., 46, 193.

\title{
Lomotil in Treatment of Post-Vagotomy Diarrhoea
}

\author{
C. D. COLLINS,* M.A., M.B., B.CHIR.
}

Brit. med.f., 1966, 2, 560-561

Diarrhoea may be defined as a deviation from established bowel rhythm characterized by an increase in frequency and fluidity of the stools. It is thought that a patient's request for relief from diarrhoea is as important as the physician's opinion in deciding whether to treat it or not. In this trial it was the patient who decided when and how often to take a course of treatment.

Diarrhoea occurring after complete vagotomy with a drainage procedure has been variously described, but may be roughly divided into three types (Cox and Bond, 1964). Transient diarrhoea occurs for a short period after the operation. This is often manifested by sudden very loose bowel actions coming on with little or no warning and lasting from a few hours to a day or two. This type disappears within three to six months of the operation. If it recurs later and the attack of diarrhoea lasts longer it can be referred to as recurrent episodic diarrhoea. The third type is an increased daily bowel frequency, sometimes of disabling severity, but most often merely of pleasing contrast to pre-operative constipation.

It was thought that tablets of Lomotil (diphenoxylate hydrochloride $5 \mathrm{mg}$. and atropine sulphate $0.05 \mathrm{mg}$.) might be of particular value in the episodic type of diarrhoea because a single dose is said to lessen the desire to defaecate after approximately one hour (Hock, 1961) and to be effective for about six hours.

A double-blind control trial was carried out in order to find out if Lomotil was of greater value than codeine phosphate in treating both the episodic' and the continual types of postvagotomy diarrhoea.

\section{Selection}

Questionaries were sent to 184 patients who had undergone a drainage procedure with complete vagotomy, as judged by the insulin test with Hollander's $(1946,1948)$ criteria in the treatment of duodenal ulcer: 154 replies were received. The follow-up period ranged from six months to six years. The patients were asked to state whether they had motions that

- Research Assistant. University Department of Surgery, Royal Infirmary, Sheffield. were (a) normally formed or (b) occasionally or always loose, (c) spasmodic attacks of diarrhoea, and $(d)$ an increased number of bowel actions per day after operation. Those who replied that they had any looseness or diarrhoea or more than two bowel actions per day were interviewed. There were 63 such patients, and 32 of them were considered to have diarrhoea of such severity as to require treatment. These were the subjects of the controlled trial. The other 31 had little more than occasional loose motions in an otherwise normal bowel habit.

\section{Method}

Each patient was given a record card with instructions to enter the number of bowel actions and the consistency of the motion each day for one month. On studying these it became clear that only 23 of the patients had diarrhoea attacks of sufficient frequency for any conclusion to be drawn regarding the benefit from the treatments they were to be given. This is in accord with the findings of Feggetter and Pringle (1963) that routine observation failed on many occasions to confirm the severity of diarrhoea complained of by patients.

These 23 patients were asked to record the number and consistency of their motions and also the number of tablets taken and their efficacy in controlling the diarrhoea over a further period of three months. The patients were each given three treatments, to be taken for one month in an order dictated by random selection. These consisted of tablets, identical in appearance and taste, of Lomotil $5 \mathrm{mg}$., of codeine phosphate $15 \mathrm{mg}$., and of placebo that was identical in appearance to both drugs but contained sucrose.

The patients were instructed to take one tablet as soon as an attack of diarrhoea began and to continue to take a tablet morning, noon, and night for three days, then stop. If the diarrhoea continued they were told to start again after a lapse of three days. All the patients except two complied with these instructions. They were seen once a month and were asked whether the tablets had been of value or had caused any sideeffects ; a new supply was given and the tablets remaining from the previous month's treatment were collected so as to avoid confusion. 


\section{Assessment}

The value of each treatment was based on three methods of assessment.

1. Stool Frequency.-The number of bowel actions in Day 0, Day 1, Day 2, and Day 3 were tabulated.

2. Clinician's Opinion.-At the completion of the threemonthly period the record cards were studied by an independent observer and were placed in order of greatest effect, as judged by the frequency and consistency of bowel actions on the day before the diarrhoea started (designated Day 0), the day on which diarrhoea began and treatment was started (Day 1), and the second and third days of treatment (Day 2 and Day 3).

3. Patient's Opinion.-Each patient was asked which month's treatment he thought was the best.

\section{Results}

Stool Frequency.-The largest number of bowel actions was recorded on Day 1. This is because 12 patients were at work without their tablets, and the diarrhoea continued for some hours before treatment was started. The number of bowel actions decreased significantly on Day 3 as compared with Day 1 in both the treated groups but not in the placebo group $(P<0.001)$ (see Chart). There was no significant difference

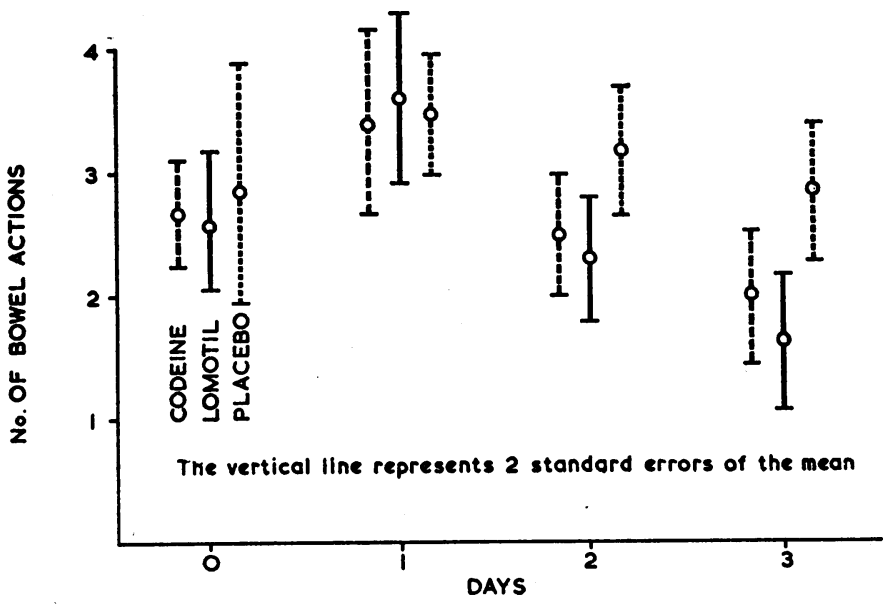

The number of bowel actions decreased significantly on Day 3 as compared with Day 1 in both the Lomotil and codeine groups but not in the placebo group. $(P<0.001$. $)$

between the Lomotil and the codeine group, the mean reduction in the number of bowel actions per day in the Lomotil group being $1.7 \pm 0.7$ and with codeine $1.3 \pm 0.7$.

The clinician's opinion and the patient's opinion are shown in the Table:

\begin{tabular}{|c|c|c|c|c|c|c|c|}
\hline & & \multicolumn{3}{|c|}{ Clinician's Opinion } & \multicolumn{3}{|c|}{ Patient's Opinion } \\
\hline & & Lotomil & Codeine & Placebo & Lomotil & Codeine & Placebo \\
\hline $\begin{array}{l}\text { First choice } . . \\
\text { Second choice .. } \\
\text { Third choice .. }\end{array}$ & $\ddot{x}$ & $\begin{array}{r}12 \\
9 \\
1\end{array}$ & $\begin{array}{r}9 \\
10 \\
3\end{array}$ & $\begin{array}{r}1 \\
3 \\
18\end{array}$ & $\begin{array}{r}12 \\
9 \\
1\end{array}$ & $\begin{array}{r}8 \\
12 \\
2\end{array}$ & $\begin{array}{r}2 \\
1 \\
19\end{array}$ \\
\hline
\end{tabular}

It will be seen that the patient's assessment closely corresponded with that of the clinician. In both assessments Lomotil was marginally preferred to codeine phosphate, though the difference was not significant. Both treatments were significantly better than the placebo ( $\chi^{2}$ with two degrees of freedom $=28.9 ; \mathrm{P}<0.001$ ).

Duration of Diarrhoea.-In all but one case the attack of diarrhoea ceased within three days of starting treatment. In this case the patient's bowels moved six to eight times daily and failed to show any improvement with treatment. Lomotil, given each day for a week in the recommended dose of 15 mg./day, did not relieve his symptoms.

Side-effects.-Side-effects were noted in 5 out of the 23 patients while they were taking Lomotil. Two complained of dryness of the mouth, two of nausea with headaches, and one woman had attacks of vomiting and dizziness on each of the three occasions in the month that she took Lomotil. One patient taking the placebo complained of abdominal pain. Codeine did not cause any side-effects.

\section{Discussion}

That Lomotil has a constipating effect cannot be doubted, but on the basis of this trial it has no significant advantage over codeine phosphate. It also gives rise to side-effects. It is doubtful if either treatment has a place in the management of post-vagotomy diarrhoea of the episodic type, because it has been found that these attacks are generally of short duration and that it is the unexpected urgency associated with the first loose motion which causes most distress. Because of the lack of warning, regular prophylaxis would be necessary, and only 2 out of the 16 patients with this type of diarrhoea said that they would prefer to take a constipating agent for this reason rather than accept the situation as it was. Of the other seven patients who had continual looseness of motions, one, as stated, did not benefit from either treatment, and the other six were given a regular supply of whichever tablet was considered to be most effective (Lomotil 4, codeine 2). Three have been markedly improved and three marginally so.

\section{Summary}

Out of 154 patients who had undergone total vagotomy with drainage 23 had diarrhoea and were the subjects of a controlled trial of Lomotil. Although Lomotil proved a satisfactory constipating agent, it is judged to be of little value in either the prophylaxis of sudden episodic attacks or the treatment of more continuous post-vagotomy diarrhoea. Sideeffects were noted in 5 of the 23 patients.

We wish to thank G. D. Searle \& Co. Ltd. for the supply of Lomotil, codeine phosphate, and placebo tablets, and Miss J. Kirkby, Pharmacist at the Hallamshire Hospital, for dispensing them.

\section{REFERENCES}

Cox, A. G., and Bond, M. R. (1964). Brit. med. F., 1, 460.

Feggetter, G. Y., and Pringle, R. (1963). Surg. Gynec. Obstet., 116, 175. Hock, C. W. (1961). F. med. Ass. Ga., 50, 485. Hollander, F. (1946). Gastroenterology, 7, 607. Hollander, F. (1946). Ibid., 11, 419. 